\title{
Kinetic Analysis of Isothermal Leaching of Zinc from Zinc Plant Residue
}

\author{
Ali Reza Eivazi Hollagh ${ }^{1}$, Eskandar Keshavarz Alamdari ${ }^{1,2}$, Davooud Moradkhani ${ }^{3}$, \\ Ali Akbar Salardini ${ }^{4}$ \\ ${ }^{1}$ Mining \& Metallurgical Engineering, Amirkabir University of Technology, Tehran, Iran \\ ${ }^{2}$ Research Center for Materials and Mining Industries Technology, Amirkabir University of Technology, \\ Tehran, Iran \\ ${ }^{3}$ Faculty of Engineering, Zanjan University, Zanjan, Iran \\ ${ }^{4}$ Materials and Energy Research Center, Tehran, Iran. \\ Email: alamdari@aut.ac.ir
}

Received December 3, 2012; revised January 2, 2013; accepted January 15, 2013

\begin{abstract}
The sulfuric acid leaching of zinc plant residues was studied in an attempt to find a suitable hydrometallurgical method for zinc recovery. The parameters evaluated consist of reaction time, Solid-to-liquid-ratio, reaction temperature, agitation rate and $\mathrm{pH}$. The results of kinetic analysis of the leaching data under various experimental conditions indicated that there is a reaction controlled by the solution transport of protons through the porous product layer with activation energy of about $1 \mathrm{~kJ} / \mathrm{mol}$ for different constant solid to liquid ratios. Based on the shrinking core model (SCM), the following semi-empirical rate equation was established:

$1-3(1-\alpha)^{\frac{2}{3}}+2(1-\alpha)=0.001187 \times\left[H^{+}\right]^{0.016} \times\left[\left(\frac{S}{L}\right)\right]^{-1.34} \times \exp \left(-\frac{1}{R T}\right) \times t$. On the other hand, activation energy was obtained from a model-free method using isothermal measurements. Values for activation energy were calculated as a result of the conversion function with an average of $2.9 \mathrm{~kJ} / \mathrm{mol}$. This value is close to that determined previously, using shrinking core model (SCM).
\end{abstract}

Keywords: Zinc; Hydrometallurgy; Kinetic Model; Zinc Plant Residue; Model-Free Method

\section{Introduction}

Zinc is an important base metal needed for different applications in metallurgical, chemical, textile [1], agricultural, painting, and rubber industries. Identified zinc resources of the world estimated by the US. Geological Survey to be about 1.9 billion tons of zinc. Zinc primary resources include zinc sulfide, carbonate, silicates and oxide minerals. Moreover, a part of zinc is recovered by different secondary resources such as zinc ash, zinc dross, flue dusts of electric arc furnace and brass smelting, automobile shredder scrap, rayon industry sludge [1] and zinc plant residues (ZPR) etc.

It was obviously observed that Pyrometallurgical and Hydrometallurgical methods or their combination could be applied for the treatment of primary and secondary zinc containing materials (ZCM). Nevertheless, when these methods are compared, the hydrometallurgical processes are more suitable for the materials with low zinc content because of their higher zinc recoveries. In addition to some other operational advantages hydrometallurgical processes are more environmentally safe and economically feasible.

Sphalerite, a zinc sulfide ore is considered as the main and primary source to produce zinc metal. Oxidative leaching is one of the major processes applied for the zinc recovery from sphalerite and many researchers have investigated its kinetic analyses [2-8].

Extensive investigations have been carried out on the treatment of zinc oxide ores by hydrometallurgical and pyrometallurgical methods [9]. For instance, Thomas and Fray [10] investigated the kinetics of leaching of zinc oxide materials by using chlorine and chlorine hydrate. In all cases studied, lead was also leached out with zinc; however, iron oxides remained almost undissolved. They applied shrinking core diffusion model to describe the kinetic analysis and found that the rate of leaching of Adrar Turkish ore was controlled by surface reaction. In another study, Frenay [11] examined the leaching of oxidized zinc ores in different solution media and gained the best leaching results by using sulfuric acid and caustic 
soda. Other workers studied the dissolution of zinc from zinc silicate ore [12-14] and carbonate ore [15].

Abdel-Aal [12] studied the kinetic leaching in sulfuric acid solution from an Egyptian zinc silicate ore and demonstrated that the diffusion through the product layer was a rate controlling process during the reaction. The kinetic dissolution of zinc from zinc silicate calcine was studied and a kinetic model of porous solids was applied to describe the rate controlling step and the rate of leaching controlled by chemical reaction and diffusion in porous solids [13].

As a result of limited availability of primary high grade zinc ores or concentrates, the recovery of zinc from secondary resources seems to be quite economical and because of their environmental issues, avoidable. First, the disposal of secondary resources is now becoming expensive because of increasingly severe environmental protection regulations. Second, due to the chemical nature of these resources, they are classified as hazardous waste in which the toxicity is mainly due to the presence of different metals such as zinc and other metals [1].

During zinc extraction process, a large amount of residues is generated daily in zinc processing plants, which is generally called zinc plant residues (ZPR) which are classified as hazardous materials since in addition to zinc; they contain lead, cadmium, arsenic etc. Due to the composition of primary zinc resources and additive chemical compounds during zinc extraction process, these residues could be an valuable sources of zinc, lead, cadmium, copper, germanium, nickel, cobalt, manganese, silver and gold.

Based on Kul and Topkaya's studies on the recovery of germanium and other valuable metals from ZPR of Çinkur Zinc Plant, the best condition for extraction of germanium and other valuable metals was reported at a temperature between 333 to 358 Kelvin temperature (K) for a leaching duration of $1 \mathrm{~h}$ with sulfuric the recoveries of mentioned valuable metals were more than $90 \%$ [16]. In another study, acid concentration of $150 \mathrm{gr} / \mathrm{L}$ and using a solid-liquid ratio of $1 / 8 \mathrm{gr} / \mathrm{cc}$. Under these conditions, Wang and Zhou recommended a hydrometallurgycal process for the production of cobalt oxide after inspecting the recovery of cobalt from ZPR [17].

ZPR has been studied for the recovery of zinc using sulphuric acid [9,16-23] and other leaching agents [24,25]; however, there is no considerable information on its kinetic analysis. Zinc is leached into diluted sulfuric acid from ZPR according to the overall reaction stoichiometry represented in Equations (1) and (2).

$$
\begin{aligned}
& \mathrm{ZnSO}_{4} \stackrel{\text { At aqueous media }}{\longrightarrow} \mathrm{Zn}^{2+}+\mathrm{SO}_{4}^{2-} \\
& \mathrm{ZnO}+\mathrm{H}_{2} \mathrm{SO}_{4} \rightarrow \mathrm{Zn}^{2+}+\mathrm{SO}_{4}^{2-}+\mathrm{H}_{2} \mathrm{O}
\end{aligned}
$$

In several investigations, summarized in Table 1, the dissolution of zinc from ZCM using hydrometallurgical method and the experimental conditions have been re- ported.

The aim of current study was to investigate factors affecting the selective leaching of zinc from ZPR with sulfuric acid. In this regard the effect of time, Solid-to-liquid-ratio(S/L), reaction temperature, agitation rate and $\mathrm{pH}$ were studied. The kinetics characterizations of the leaching process were analyzed in accordance with shrinking core model (SCM) and the order of reaction with respect to $\mathrm{pH}$ and Solid-to-liquid-ratios. Based on the experimental and calculated results, a semi-empirical rate equation was presented. The activation energy of the dissolution process was evaluated by applying the shrinking-core-model method in the temperature range of 298 $353 \mathrm{~K}$. In addition, the model-free method was employed in order to estimate the activation energy during the reaction and completion of kinetics investigation. The kinetics results by using model-free method could be useful and confirming for determined leaching mechanism by shrinking core model (SCM). The kinetics characterization of the selective leaching of zinc from ZPR is nessecery for future design of zinc recovery from this hazardous and high content zinc materials. Residue of zinc leaching from ZPR in diluet sulfuric acid may be collected for further cobalt, manganese and zinc recovery.

\section{Theory of the Kinetic Modeling}

\subsection{Shrinking Core Model}

In many practical cases, fluid-solid reactions can indeed be approximated as the first-order reactions for mathematical simplicity [28].

Leaching process of ZCM in acid [2-7,9,12] and ammonia $[29,30]$ follows a kinetic model known as shrinking-core-model (SCM). This model should be employed for the first-order reactions and considers whether the rate of leaching process is controlled by the diffusion of reactant or the rate of the surface chemical reaction. The heterogeneous leaching reaction can be expressed as follows:

$$
\mathrm{A}_{\text {fluid }}+\mathrm{bB}_{\text {solid }} \rightarrow \text { Fluid product }+ \text { Solid products }
$$

A review of the integrated forms of kinetic laws $(\mathrm{G}(\alpha))$ for different control regimes known in ZCM leaching according to Levenspiel is detailed in Table 2 [31].

Based on the Arrhenius law, the reaction rate constant is expressed by the Equation (7):

$$
k=A \exp \left(\frac{-E}{R T}\right)
$$

where, $k$ is the kinetic constant, $A$ is the pre-exponential factor, $E$ is the activation energy, $T$ is temperature and $R$ is the gas constant.

The kinetic parameters $E$ and $A$ can be obtained using shrinking core model (SCM). When the integrated form of the kinetic law i.e. $G(\alpha)=k t$ is known, then one can 
Table 1. Summary of the recent researches conducted by various workers on the leaching of Zn from ZCM.

\begin{tabular}{|c|c|c|c|c|}
\hline $\mathrm{ZCM}$ & Leaching Media & $\begin{array}{l}\text { Temp } \\
(\mathrm{K})\end{array}$ & Description & Ref. \\
\hline $\begin{array}{l}\text { Tailings with high } \\
\text { zinc content }\end{array}$ & $\mathrm{H}_{2} \mathrm{SO}_{4}(2 \mathrm{M})$ & 333 & $\begin{array}{c}\text { Maximum zinc recovery }=98 \%, \text { Duration }=7200 \mathrm{sec}, \text { Agitation rate }=480 \mathrm{rpm}, \\
\text { Solid-Liquid-Ratio }(\mathrm{S}: \mathrm{L})=1: 4 \text {, Particle size }=-75+53 \mu \mathrm{m}\end{array}$ & [9] \\
\hline $\mathrm{Pb}$ bearing $\mathrm{ZPR}$ & $\mathrm{H}_{2} \mathrm{O}+\mathrm{H}_{2} \mathrm{SO}_{4}$ & 353 & $\begin{array}{l}\text { Maximum zinc recovery }=69.3 \%, \text { Duration }=3600 \mathrm{sec}, \mathrm{pH} \text { of solution }=2.5 \text {, } \\
\text { Agitation rate }=\text { Good mixing, } \mathrm{S}: \mathrm{L} \text { ratio }=1: 5, \text { Particle size }=-180+30 \mu \mathrm{m}\end{array}$ & [19] \\
\hline ZPR & $150 \mathrm{gr} / \mathrm{L} \mathrm{H}_{2} \mathrm{SO}_{4}$ & 358 & $\begin{array}{c}\text { Maximum zinc recovery }>95 \% \text {, Duration }=3600 \mathrm{sec} \text {, Agitation rate }=\text { Good mixing, } \\
\text { S:L ratio }=1: 4, \text { About } 84 \% \text { of particle size }<147 \mu \mathrm{m}\end{array}$ & [16] \\
\hline ZPR & $\mathrm{H}_{2} \mathrm{SO}_{4}(0.5 \mathrm{M})$ & 348 & $\begin{array}{c}\text { Maximum zinc recovery }>96 \%, \text { Duration }=1800 \mathrm{sec}, \text { Agitation rate }=\text { Good mixing, } \\
\text { S:L ratio }=1: 10, \text { Particle size }=-\end{array}$ & {$[17]$} \\
\hline Blended leach residue & $150 \mathrm{gr} / \mathrm{L} \mathrm{H}_{2} \mathrm{SO}_{4}$ & 368 & $\begin{array}{l}\text { Maximum zinc recovery }=71.9 \%, \text { Duration }=7200 \mathrm{sec} \\
\quad \text { Agitation rate }=250 \mathrm{rpm}, \text { Solid:Liquid ratio }=1: 5\end{array}$ & {$[18]$} \\
\hline Sphalerite concentrate & $5 \% \mathrm{H}_{2} \mathrm{SO}_{4}+5 \% \mathrm{H}_{2} \mathrm{O}_{2}$ & 333 & $\begin{array}{c}\text { Maximum zinc recovery }=80 \% \text {, Duration }=14,400 \mathrm{sec}, \text { Agitation rate }=160 \mathrm{rpm}, \\
\text { S:L ratio }=1: 20, \text { Particle size } \leq 38 \mu \mathrm{m}\end{array}$ & [27] \\
\hline \multirow{4}{*}{$\begin{array}{l}\text { Low-grade zinc } \\
\text { silicate ore }\end{array}$} & $\begin{array}{c}5 \%(\mathrm{~V} / \mathrm{V}) \mathrm{H}_{2} \mathrm{SO}_{4}+ \\
5 \%(\mathrm{~W} / \mathrm{V}) \text { ammonium } \\
\text { persulphates }\end{array}$ & 333 & $\begin{array}{l}\text { Maximum zinc recovery }=95 \%, \text { Duration }=18000 \mathrm{sec}, \text { Agitation rate }=\text { Good mixing, } \\
\text { S:L ratio }=1: 10, \text { Particle size } \leq 150 \mu \mathrm{m}\end{array}$ & {$[2]$} \\
\hline & $\begin{array}{l}1 \mathrm{M} \mathrm{H}_{2} \mathrm{SO}_{4}+ \\
0.5 \mathrm{M}\left[\mathrm{Fe}^{3+}\right]\end{array}$ & 333 & $\begin{array}{l}\text { Maximum zinc recovery }=73 \% \text {, Duration }=18000 \mathrm{sec} \text {, Agitation rate }=480 \mathrm{rpm}, \\
\qquad \mathrm{S}: \mathrm{L} \text { ratio }=1: 200, \text { Particle size }=-75+53 \mu \mathrm{m}\end{array}$ & {$[3]$} \\
\hline & $\begin{array}{l}2 \mathrm{M} \mathrm{H}_{2} \mathrm{SO}_{4}+ \\
0.2 \mathrm{M} \mathrm{HNO}_{3}\end{array}$ & 358 & $\begin{array}{l}\text { Maximum zinc recovery }=99.6 \%, \text { Duration }=10800 \mathrm{sec}, \text { Agitation rate }=\text { Good mixing, } \\
\mathrm{PO}_{2}=0.1 \mathrm{MPa}, \mathrm{S}: \mathrm{L} \text { ratio }=1: 10, \text { Particle size }<74 \mu \mathrm{m}, \mathrm{C}_{2} \mathrm{Cl}_{4}: \text { Leaching solution }=1: 20\end{array}$ & [7] \\
\hline & $10 \% \mathrm{H}_{2} \mathrm{SO}_{4}$ & 343 & $\begin{array}{c}\text { Maximum zinc recovery }=94 \%, \text { Duration }=10800 \mathrm{sec}, \text { Agitation rate }=550 \mathrm{rpm}, \\
\text { S:L ratio }=1: 20, \text { Particle size }=-200+270 \text { mesh }\end{array}$ & [12] \\
\hline Zinc silicate calcine & $0.4 \mathrm{M} \mathrm{H}_{2} \mathrm{SO}_{4}$ & 333 & $\begin{array}{l}\text { Maximum zinc recovery }=95 \% \text {, Duration }=420 \mathrm{sec} \text {, Agitation rate }=480 \mathrm{rpm}, \\
\qquad \mathrm{S}: \mathrm{L} \text { ratio }=1: 100, \text { Particle size }=75-53 \mu \mathrm{m}\end{array}$ & [13] \\
\hline
\end{tabular}

Table2. Set of control regimes according to shrinking core model (SCM) [31].

\begin{tabular}{|c|c|c|c|}
\hline Control regimes & $G(\alpha)$ & $k$ & Equation \\
\hline Liquid film diffusion & $1-(1-\alpha)^{\frac{2}{3}}$ & $\frac{2 b D C_{A}}{\rho R_{\circ}^{2}}$ & 4 \\
\hline Solid product diffusion & $1-3(1-\alpha)^{\frac{2}{3}}+2(1-\alpha)$ & $\frac{2 b D C_{A}}{\rho R_{\circ}}$ & 5 \\
\hline Chemical reaction & $1-(1-\alpha)^{\frac{1}{3}}$ & $\frac{2 b D k_{\circ} C_{A}}{\rho R_{\circ}^{2}}$ & 6 \\
\hline
\end{tabular}

$G(\alpha)$ : Reaction model; $k$ : Reaction rate constant; $\underline{k}_{d}$ : reaction rate constant when diffusion is rate controller; $k_{C}$ : reaction rate constant when chemical reaction is rate controller; $\alpha$ : Fraction reacted; $b$ : Stoichiometric coefficient of reaction; $D$ : diffusion coefficient in the porous product layer; $C_{A}$ : Concentration of the leachant in the solution; $\rho$ : Density of the solid particle; $R_{o}$ : Radius of the unreacted particle; $K_{o}$ : Kinetic constant; 
plot the values of $G(\alpha)$ against time for different isothermal experiments. Each of these plots should be linear, the slope being the value of $k$ at that temperature. Since:

$$
\ln k=\ln A-\frac{E}{R T}
$$

The plot of $\ln k$ versus reciprocal temperature would be a straight line. The slope of straight line gives $-E / R$ and intercepts $\ln A$. In this method, there is also an implicit assumption that the activation energy $E$ does not change during the course of reaction.

\subsection{Theory of Model-Free Method}

If the $G(\alpha)$ is unknown then evaluation of activation energy $E$ by the integral approach is useless. In addition, in the previous method it was assumed the the evaluated $E$ does not change during the reaction. In model-free method the activation energy should be accepted as a variable parameter, therefore, $E$ can be calculated at different level of $\alpha$. In general, the integral form of the rate equation is written as:

$$
G(\alpha)=k t
$$

where, $G(\alpha)$ is an appropriate function of $\alpha$. By differenttiating with regard to time:

$$
\begin{gathered}
G^{\prime}(\alpha) \cdot \frac{\mathrm{d} \alpha}{\mathrm{d} t}=k \\
\frac{\mathrm{d} \alpha}{\mathrm{d} t}=\frac{k}{G^{\prime}(\alpha)}=k \cdot f(\alpha)
\end{gathered}
$$

So, $f(\alpha)$ in the differential form of rate equation equals $\frac{1}{G^{\prime}(\alpha)}$. We have, from Equation (7) and (11):

$$
\frac{\mathrm{d} \alpha}{\mathrm{d} t}=k \cdot f(\alpha)=A \cdot \exp \left(\frac{-E}{R T}\right) \cdot f(\alpha)
$$

Considering a fixed value of $\alpha$, Equation (12) can be rewritten as follows:

$$
\int_{0}^{\alpha} \frac{\mathrm{d} \alpha}{f(\alpha)}=A \cdot \exp \left(\frac{-E}{R T}\right) \int_{0}^{t_{\alpha}} \mathrm{d} t
$$

And/or:

$$
\frac{1}{A \cdot \exp \left(\frac{-E}{R T}\right)} \int_{0}^{\alpha} G^{\prime}(\alpha) \mathrm{d} \alpha=\int_{0}^{t_{\alpha}} \mathrm{d} t
$$

Then:

$$
\frac{G(\alpha)}{A \cdot \exp \left(\frac{-E}{R T}\right)}=t_{\alpha}
$$

Hence:

$$
-\ln t_{\alpha, i}=\ln \left[\frac{A_{\alpha}}{G(\alpha)}\right]-\frac{E_{\alpha}}{R T_{i}}
$$

In the Equation (16) subscripts, $i$ refer to isothermal condition $[32,33] . t_{\alpha, i}$ is the time required to reach a certain conversion isothermal, and $A_{\alpha}$ and $G(\alpha)$ represent pre-exponential factor and integrated form of the reaction model.

For the fixed value of $\alpha$, it follows that a plot of the left side of equation (16) against reciprocal temperature would be a straight line; the slope of which should yield the value of $-E / R$. So, $E$ can be calculated at different levels of $\alpha$.

\section{Materials and Reagents}

The zinc plant residue used in the experiments was obtained from the National Lead and Zinc Co. (NILZ); Zanjan, Iran which has a production capacity of $20000 \mathrm{t}$ $\mathrm{Zn} / \mathrm{y}$. In this company, $\mathrm{ZnO}$-rich calcine is first produced from the oxide-carbonate concentrates and then leached with hot sulfuric acid solution. After the separation of liquid and solid, the pregnant solution is purified by selective precipitation method and cementation. Finally, the purified solution is electrowon for metallic zinc production. The separated solids during each stage are called ZPR. A flow sheet which explains each purification stage in NILZ plant is reported in literature [34].

The ZPR used in this study initially contained ca. $20 \%$ moisture. Prior to the use, the sample was dried, ground, and homogenized using a riffle; and then was crushed using a ball mill. At this stage, due to the nature of ZPR, its fractionation by dry screen test was not possible. Therefore, the samples were directly used for the experiments without any particle size fractionation and some preliminary tests such as Scanning Electron Micrograph pictures taken (Figure 1), which showed that its particle size was generally less than $50 \mu \mathrm{m}$.

After homogenizing ZPR, a sample was taken for its kinetics study. The chemical analysis of the sample was carried out by atomic absorption spectrometer (PerkinElmer AA300 atomic). The details of the chemical analysis of ZPR sample was; $\mathrm{Zn}=28.39 \%, \mathrm{Mn}=5.53 \%$, Co $=$ $0.66 \%, \mathrm{Ca}=9.77 \%$. The XRF analytical results are shown in Table 3. The results indicated that the ZPR was mostly composed of zinc, calcium, manganese and cobalt.

In the previous researches, the mineralogical characterization of ZPR for zinc compounds have been identified as follows: $\left.(\mathrm{Zn}, \mathrm{Cu})_{2}\left(\mathrm{AsO}_{4}\right) \mathrm{OH}\right)$, zinc oxysulphate $\left(\mathrm{Zn}_{3} \mathrm{O}\left(\mathrm{SO}_{4}\right)_{2}\right)[16]$, hydrated zinc sulfate $\left(\mathrm{ZnSO}_{4} \cdot \mathrm{XH}_{2} \mathrm{O}\right)$ $[16,18,19]$, hydrated zinc sulfite $\left(\mathrm{ZnSO}_{3} \cdot 2.5 \mathrm{H}_{2} \mathrm{O}\right)[16,34]$, zinc oxide $(\mathrm{ZnO})$ [34], zinc ferrite $\left(\mathrm{ZnFe}_{2} \mathrm{O}_{4}\right)$ [18]. Different compounds of zinc was detected from different 


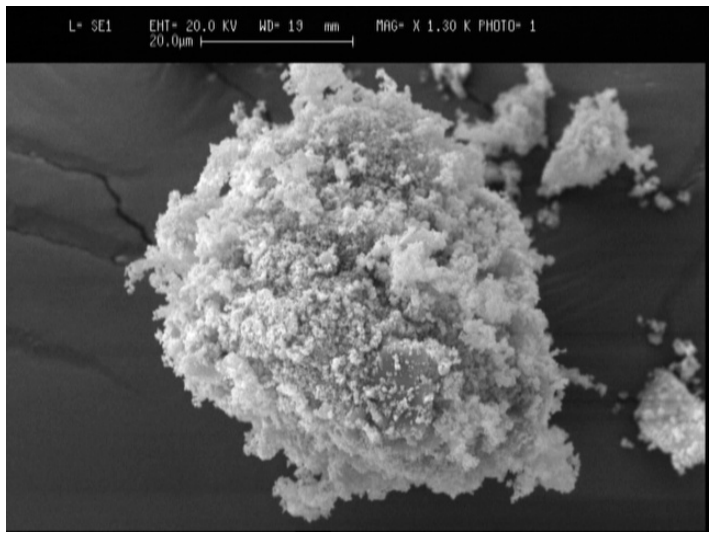

Figure 1. Scanning electron micrograph of ZPR particles.

Table 3. XRF analysis of used ZPR used in this study.

\begin{tabular}{cc}
\hline Chemical composition & Conc.\% \\
\hline $\mathrm{Mn}$ & 4.97 \\
$\mathrm{Si}$ & 1.00 \\
$\mathrm{~S}$ & 10.96 \\
$\mathrm{Ca}$ & 11.51 \\
$\mathrm{Fe}$ & 0.11 \\
$\mathrm{Co}$ & 0.71 \\
$\mathrm{Zn}$ & 25.96 \\
$\mathrm{~Pb}$ & 0.17 \\
$\mathrm{Cd}$ & 0.10 \\
$\mathrm{Mg}$ & 0.22 \\
$\mathrm{Al}$ & 0.40 \\
$\mathrm{~K}$ & 0.15 \\
\hline
\end{tabular}

kind of produced ZPRs in zinc plants. Mineralogical analysis performed using Philips PW3710 model X-ray diffractometer, which indicated that

$\mathrm{ZnSO}_{4} \cdot 3 \mathrm{Zn}(\mathrm{OH})_{2} \cdot 4 \mathrm{H}_{2} \mathrm{O}, \mathrm{Zn}_{4} \mathrm{O}_{3}\left(\mathrm{SO}_{4}\right) \cdot 7 \mathrm{H}_{2} \mathrm{O}, \mathrm{ZnSO}_{4} \cdot \mathrm{H}_{2} \mathrm{O}$, $\mathrm{CaSO}_{4} \cdot 0.5 \mathrm{H}_{2} \mathrm{O}, \mathrm{MnO}_{2}$ and $\mathrm{Co}_{2} \mathrm{O}_{3}$ were the main mineralogical composition in the used ZPR (Figure 2). Distilled water was used in the experiments which were performed under atmospheric pressure. Laboratory grade sulfuric acid was used to adjust the solution $\mathrm{pH}$ as required.

\section{Experimental Method}

For the kinetic study, experiments were carried out in 4.5 L stainless steel rectangular boxes $(14 \times 14 \times 23(\mathrm{~L} \times \mathrm{W}$ $\times \mathrm{H}) \mathrm{cm}$ ) placed in a water bath equipped with a mechanical stirrer. The bath temperature was digitally controlled within $\pm 273.5 \mathrm{~K}$ (Figure 3). There were four baffles $(17 \times 3 \mathrm{~cm})$ in reaction vessel. The impeller was

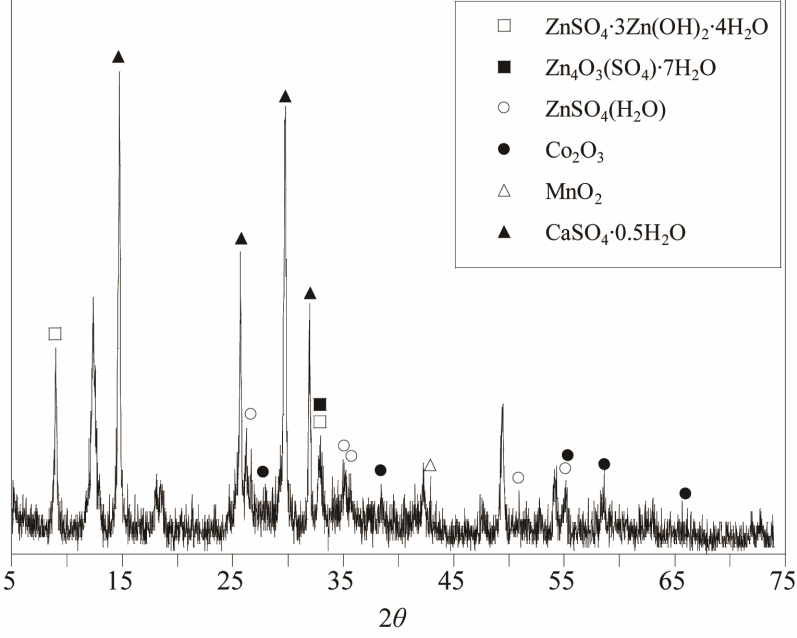

Figure 2. X-ray diffraction analysis of the ZPR used in this study.

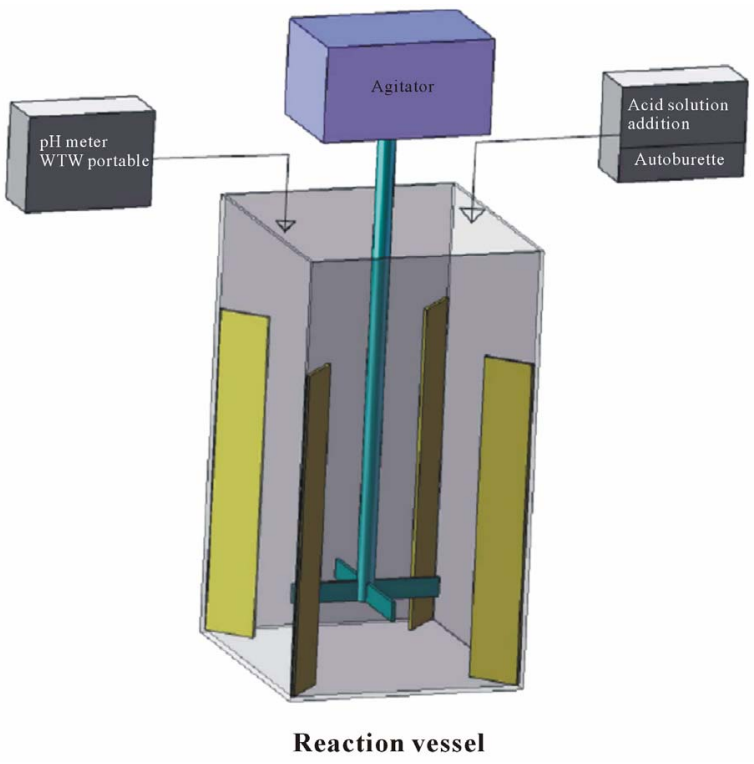

Figure 3. Schematic diagram of the reaction vessel during the kinetics study.

placed $3 \mathrm{~cm}$ above the bottom of the vessel. During the experiment, the agitation rate was adjusted in the range of 50 to $1000 \mathrm{rpm}$; temperature was varied in the range of 298 to $353 \mathrm{~K}$; $\mathrm{pH}$ was adjusted at 1 to 5 ; solid to liquid ratio was changed in the range of $1 / 8$ to $1 / 4(\% \mathrm{~W} / \mathrm{V})$; the applying maximum time of reaction is $7200 \mathrm{sec}$. When the solution temperature reached the desired value, the dried ZPR powder was added to the solution with an initial volume of $3 \mathrm{~L}$. At certain intervals, samples of known volume were taken from the pulp. The samples were immediately vacuum filtered, diluted and analyzed for the zinc concentration, which was calculated with respect to the correction of volume [35]. The $\mathrm{H}_{2} \mathrm{SO}_{4}$ concentration in all cases was $238 \mathrm{gr} / \mathrm{L}$. Any volume of 
sulfuric acid solution was used to adjust the $\mathrm{pH}$ of the solution as was required. The $\mathrm{pH}$ was measured using a WTW portable pH-meter equipped with a suitable electrode for aqueous solution and an automatic temperature compensation device.

\section{Result and Discussion}

\subsection{Effect of Agitation}

Agitation of pulps is usually necessary to maximize the kinetics and short reaction times in order to make it desirable for economic reasons [30]. In some leaching processes, maximization of reaction kinetics is being performed by increasing the agitation rate, so that the mineral particles could remain suspended in the liquor and induce a decrease in the thickness of the mass transfer boundary layer on the surface of the particles. By increasing the agitation rate, therefore, the diffusion of liquor to the surface of the particles increases [36]. The effect of agitation rate on the dissolution of zinc was investigated at various agitation rates $(50,250,450,700$ and $1000 \mathrm{rpm}$ ) at $333 \mathrm{~K}$ and $\mathrm{pH}$ of 3 and with solid/liquid ratio of $1 / 6 \%(\mathrm{~W} / \mathrm{V})$ after $3600 \mathrm{sec}$. As Figure 4 indicates, dissolution of zinc was affected by changes in agitation rate. The results show that the leaching rate of zinc increases quickly below $450 \mathrm{rpm}$ and remains almost constant beyond this speed to 1000 rpm. The maximum zinc recovery under this condition was more than $80 \%$ when $1000 \mathrm{rpm}$ agitation rate was applied; however, this agitation rate may not be applicable in industrial operations due to the increase in the capital and opera compromised optimum operating agitation rate.

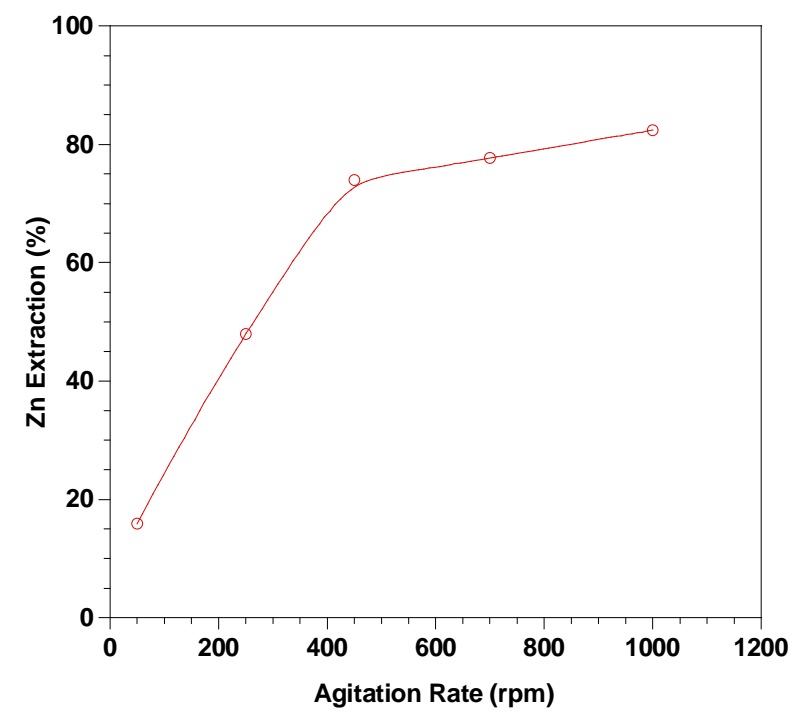

Figure 4. Effect of agitation rate on the zinc recovery from the ZPR, (pH: 3; temperature: 333 K; Solid-to-liquid-ratio: 1/6; time: $4200 \mathrm{sec})$.

\subsection{Effect of Temperature}

Experiments were performed to study the temperaturedependency of the reaction to the amount of zinc extracted. Figure 5 shows that, zinc extraction increased along with the leaching time. Figure 5 also indicates that increasing the temperature from 298 to $353 \mathrm{~K}$ did not improve this leaching system. There was some improvement in the zinc extraction upon increasing the temperature up to $353 \mathrm{~K}$, but in different reaction time. About $95 \%$ of zinc could be extracted at $333 \mathrm{~K}$ within $5400 \mathrm{sec}$.

Temperature dependency can be used to estimate the apparent activation energy, enthalpy of activation and entropy of activation [37]. It is widely accepted [31] that systems with an activation energy greater than $40 \mathrm{~kJ} / \mathrm{mol}$ are controlled by a chemical reaction while those with an activation energy of about $10 \mathrm{~kJ} / \mathrm{mol}$ or less are controlled by a transport process whether in the product layer or a boundary fluid film.

Based on shrinking core model (SCM) results, Equations (5) and (6) were applied for the results obtained from each temperature value. Figure 6 represents the data plot according to chemical reaction control. The slope of the line is the rate constant $\mathrm{k}_{\mathrm{c}}$. Figure 7 also shows the data plot according to diffusion control process. The slope of this line is considered as the apparent rate constant $\mathrm{k}_{\mathrm{d}}$. The rate constant values, $\mathrm{k}_{\mathrm{d}}$ and $\mathrm{k}_{\mathrm{c}}$ are calculated from Equations (5) and (6), respectively. The results obtained from Figures 6 and 7 indicated that the dissolution rate of ZPR was controlled by the diffusion and not the surface chemical reactions. That was due to lower value of correlation coefficients $\left(\mathrm{R}^{2}\right)$ of chemical reaction model than the value of $\mathrm{R}^{2}$ of ash diffusion

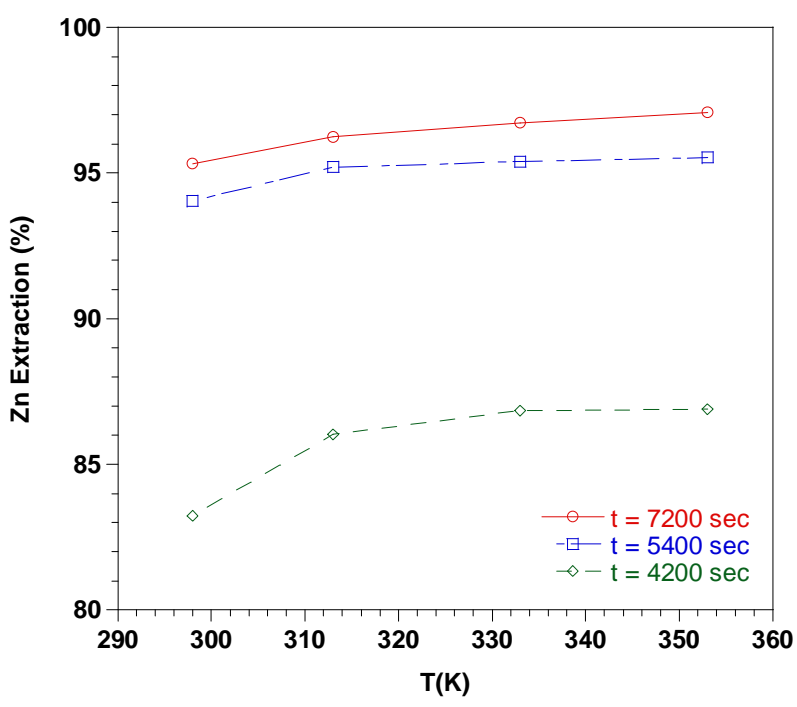

Figure 5. Effect of temperature on the zinc recovery from the ZPR in various times, (solid-liquid-ratio: 1/6; pH: 3; agitation rate: $700 \mathrm{rpm}$ ). 


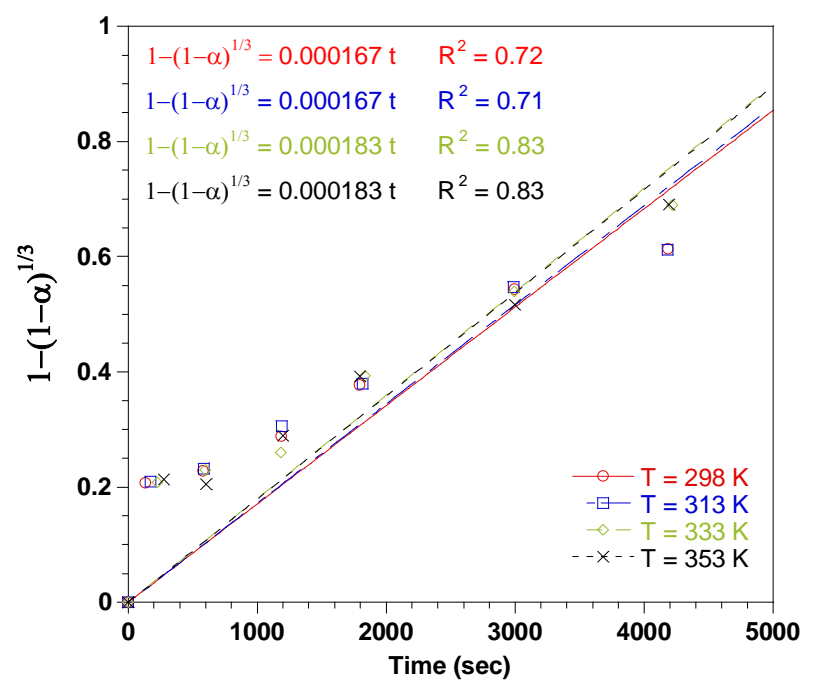

Figure 6. Plot of $1-(1-\alpha)^{1 / 3}$ vs time for different temperatures (Solid-to-liquid-ratio: 1/8; agitation rate: 700 rpm; $\mathbf{p H}$ : 3).

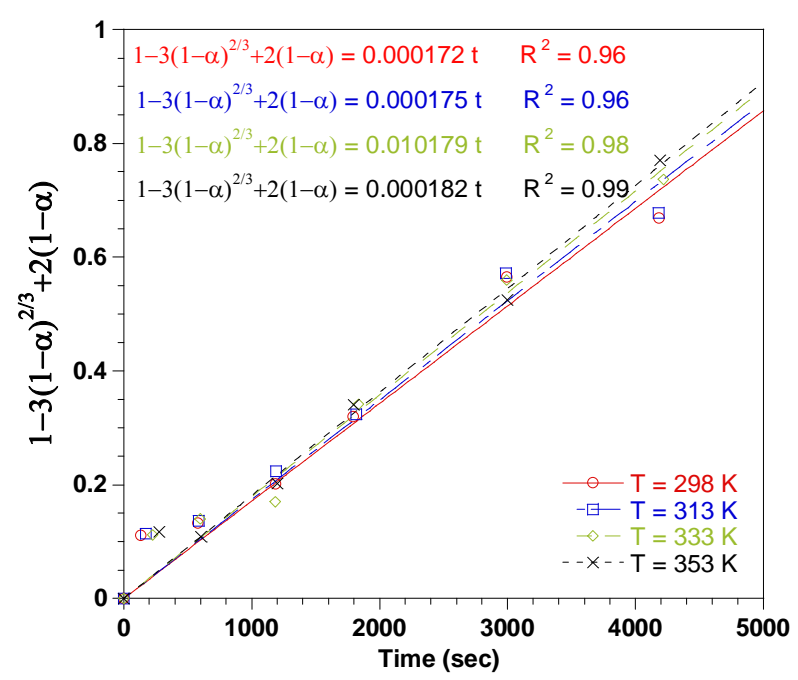

Figure 7. Plot of $1-3(1-\alpha)^{2 / 3}+2(1-\alpha)$ vs time for different temperatures, (Solid-to-liquid-ratio: 1/8; agitation rate: 700 rpm; pH: 3).

model. The apparent rate constant for zinc dissolution increases slightly by increasing the temperature up to 353 $\mathrm{K}$. Generally, a high value of activation energy indicates that the process is strongly influenced by temperature and therefore, the rate-controlling step could have a reaction at the solid surface. Conversely, a low value of activation energy indicates that the process is weakly influenced by the temperature and the rate-controlling step could be the mass transport of reagents or products through the reaction product.

The results that are given in Table 4, show that the dissolution of ZPR in the different Solid-to-liquid-ratios and temperature range of 298 - $353 \mathrm{~K}$ fitted the diffusion model given in Equation (5).
Arrhenius plot (Figure 8) presenting the apparent rate constants was obtained by applying Equation (5) to leaching experimental data (Figure 8). As seen in Figure $\mathbf{8}$, the calculated activation energy for each Solid to liquid ratio was about $1 \mathrm{~kJ} / \mathrm{mol}$ which clearly suggests that diffusion controls the leach process [31]. Due to low value of activation energy, increasing the temperature would not affect its occurrence significantly.

Model-free method has been used by other investigators for solid-gas reactions to estimate the Arrhenius parameters, but the current method is also applied to investigate the kinetic study in solid-liquid reaction [38].

Table 4. zinc leaching experimental conditions and results in constant pH of 3 .

\begin{tabular}{|c|c|c|c|c|c|}
\hline $\mathrm{S} / \mathrm{L}$ ratio $(\% \mathrm{wt} / \mathrm{v})$ & Temp. (K) & Time (sec) & $\mathrm{Zn} \% \mathrm{E}$ & $\mathrm{k}_{\mathrm{d}}\left(\sec ^{-1}\right)$ & $\mathrm{R}^{2}$ \\
\hline \multirow{4}{*}{$1 / 8$} & 298 & 4200 & 94.230 & 0.000172 & 0.96 \\
\hline & 313 & 4200 & 94.268 & 0.000175 & 0.96 \\
\hline & 333 & 4200 & 96.970 & 0.000179 & 0.98 \\
\hline & 353 & 4200 & 97.000 & 0.000182 & 0.99 \\
\hline \multirow{4}{*}{$1 / 6$} & 298 & 5400 & 94.047 & 0.000125 & 0.97 \\
\hline & 313 & 5400 & 95.204 & 0.000128 & 0.98 \\
\hline & 333 & 5400 & 95.384 & 0.000131 & 0.98 \\
\hline & 353 & 5400 & 95.534 & 0.000133 & 0.99 \\
\hline \multirow{4}{*}{$1 / 4$} & 298 & 7200 & 87.104 & $6.83 \mathrm{E}-05$ & 0.98 \\
\hline & 313 & 7200 & 88.380 & $6.97 \mathrm{E}-05$ & 0.97 \\
\hline & 333 & 7200 & 91.547 & $7.14 \mathrm{E}-05$ & 0.96 \\
\hline & 353 & 7200 & 91.891 & $7.34 \mathrm{E}-05$ & 0.93 \\
\hline
\end{tabular}

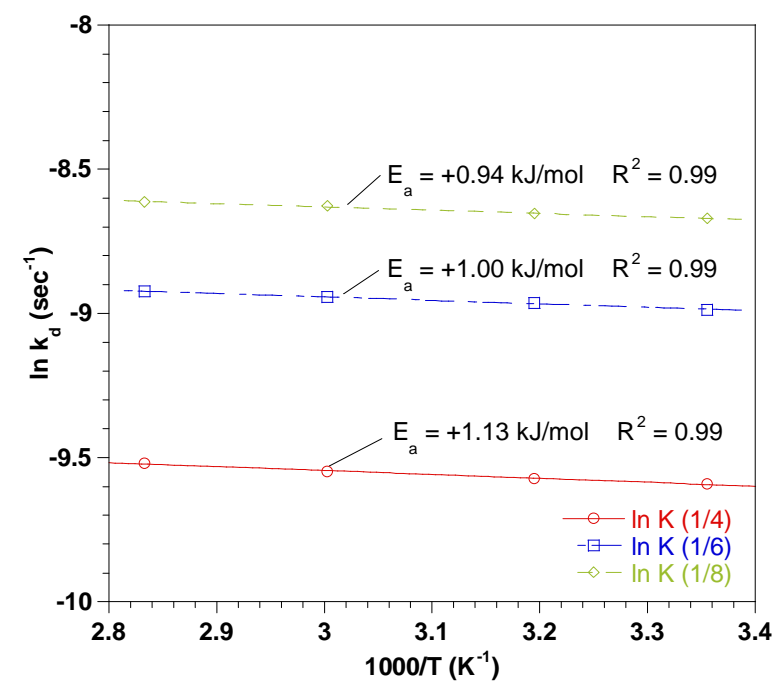

Figure 8. Arrhenius plot of reaction rate against reciprocal temperature in different Solid-to-liquid-ratios, (agitation rate: 700 rpm; pH: 3). 
Vya zovkin and Wright compared the model-free and model fitting methods in solid reaction and the activation energy was estimated by the model-free method [32]. In this method, $t_{\alpha}$, the time required for a given value of $\alpha$ was calculated first and then activation energy was obtained by applying Equation (16) to isothermal kinetic data within the range of 0.50 to 0.95 . Values for $E$ were achieved as a function of conversion with an average of $2.9 \mathrm{~kJ} / \mathrm{mol}$ (Figure 9). This value is close to that determined previously, using shrinking core model (SCM).

It may be observed from Figure 9 that dependency of activation energy on conversion is rather weak, decreasing at the range of 0.50 to 0.95 . The changes in $\mathrm{E}$ with conversion may be described as follows. Nucleation of ash, nuclei growth and diffusion of the liquid reagent through the porous ash provide the effective parameters that will determine the activation energy. The results of BET surface area analyzing, show that by increasing the time of leaching the surface area of particles are risen. This could confirm the porosity in the product ash (Figure 10). As compared with the activation energy at range of 0.50 to 0.95 , the high value of activation energy at $\alpha=$ 0.5 may be explained by interaction of these phenomena. Decrease in activation energy could be illustrated by noting that at studied range; the product layer imposes a negligible resistance to the overall rate. However, as the result of nuclei growth during the reaction, the activation energy decreases.

\subsection{Effect of pH}

The effect of $\mathrm{pH}$ in the range of $1-5$ was studied at $333 \mathrm{~K}$ with a stirring speed of $700 \mathrm{rpm}$ for Solid-to-liquid-ratio of $1 / 6$. Sulfuric acid solution was used to adjust the $\mathrm{pH}$ of the solution as was required. As seen in Figure 11, the

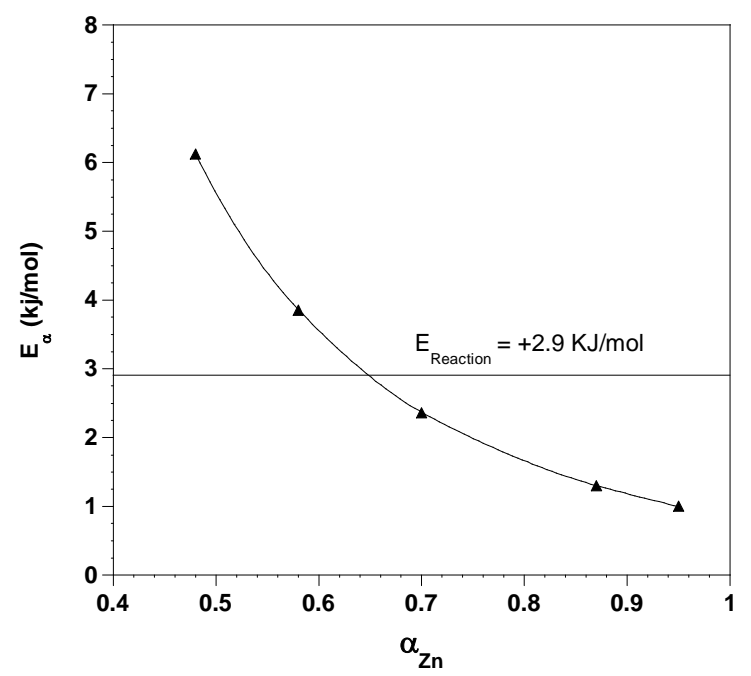

Figure 9. Variation of the activation energy with conversion derived from model-free method applying isothermal kinetic data.

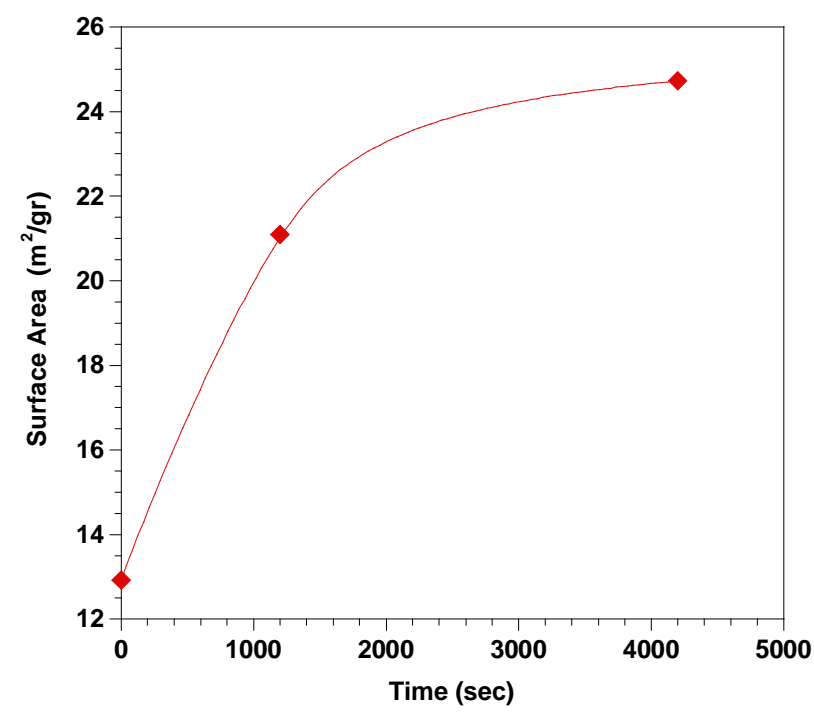

Figure 10. Variation of the surface area vs time, (Solid-toliquid-ratio: 1/6; agitation rate: $700 \mathrm{rpm}$; $\mathrm{pH}: 3$, temperature: $333 \mathrm{~K})$.

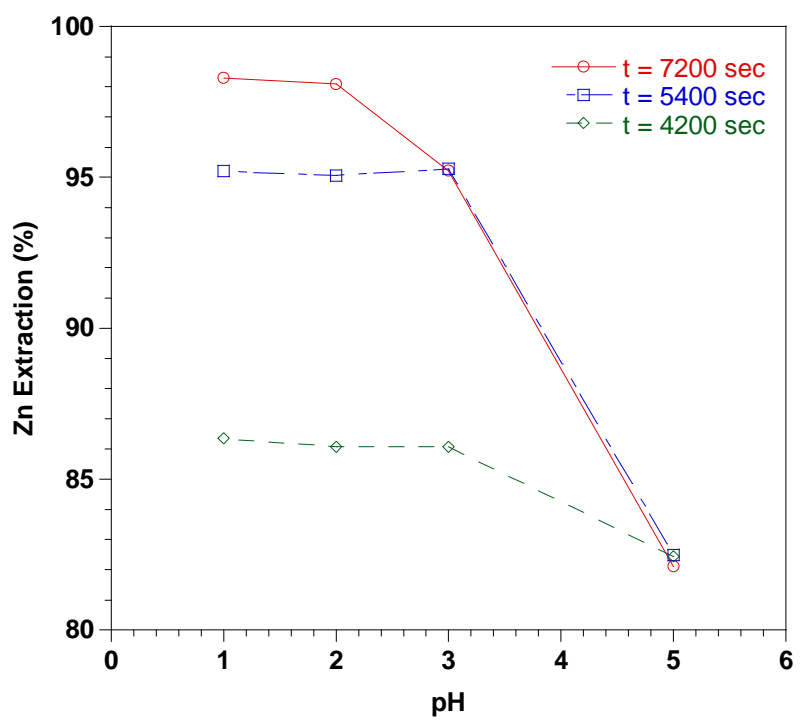

Figure 11. Effect of $\mathrm{pH}$ on the zinc recovery from the ZPR in various times (Solid-to-liquid-ratio: 1/6; temperature: $333 \mathrm{~K}$; agitation rate: $700 \mathrm{rpm}$ ).

dissolution of zinc was improved by decreasing in $\mathrm{pH}$ until 3, but further decreasing of $\mathrm{pH}$ had no significant effect. It could be also seen in this figure that the zinc extraction efficiencies were developed along with the increasing leaching time at constant $\mathrm{pH}$ of 1,2 and 3 . For $\mathrm{pH}$ of 5 , the maximum extraction of zinc is approximately $81 \%$. On the other hand, the maximum zinc dissolution at $\mathrm{pH}$ of 3,2 and 1 was about $95 \%, 98 \%$ and $98 \%$, respectively. So, the lowest zinc recovery was at $\mathrm{pH}$ of 5 . Based on the XRD analysis of ZPR, it could be concluded that most of the zinc in ZPR was as zinc sulfate and oxide. Zinc is leached from detected zinc minera- 
logical composition of ZPR base on XRD analysis of ZPR in diluted sulfuric acid according to the following reaction stoichiometry:

$$
\begin{aligned}
& \mathrm{ZnSO}_{4} \cdot 3 \mathrm{Zn}(\mathrm{OH})_{2} \cdot 4 \mathrm{H}_{2} \mathrm{O}+3 \mathrm{H}_{2} \mathrm{SO}_{4} \\
& \rightarrow 4 \mathrm{Zn}^{2+}+4 \mathrm{SO}_{4}^{2-}+7 \mathrm{H}_{2} \mathrm{O} \\
& \quad \mathrm{Zn}_{4} \mathrm{O}_{3} \cdot\left(\mathrm{SO}_{4}\right) \cdot 7 \mathrm{H}_{2} \mathrm{O}+3 \mathrm{H}_{2} \mathrm{SO}_{4} \\
& \quad \rightarrow 4 \mathrm{Zn}^{2+}+4 \mathrm{SO}_{4}^{2-}+10 \mathrm{H}_{2} \mathrm{O} \\
& \mathrm{ZnSO}_{4} \cdot 0.5 \mathrm{H}_{2} \mathrm{O} \\
& \stackrel{\text { At aqueous media }}{\longrightarrow} \mathrm{Zn}^{2+}+\mathrm{SO}_{4}^{2-}+0.5 \mathrm{H}_{2} \mathrm{O}
\end{aligned}
$$

However, in all experiment less than 5\% Co, Mn and Ca were leached from ZPR.

Due to the low acidity of the solution in $\mathrm{pH}$ of 5 most of the zinc was liberated from the zinc sulfate phase of the ZPR and smaller amount was released from zinc oxide phase. However, because of high acidity in $\mathrm{pH}$ of 1 and 2 during reaction, the remittance of the zinc was recovered from the zinc oxide and the maximum dissolution was improved further. Nevertheless, it was concluded that there was no benefit in decreasing the $\mathrm{pH}$ beyond 3 as the cost of consumption of acid to obtain $\mathrm{pH}$ of 1 and 2 is very high. Thus leaching at $333 \mathrm{~K}$ and $\mathrm{pH}$ of 3 after $5400 \mathrm{sec}$ was selected to be practically optimum.

To further examine the effect of $\mathrm{pH}$ applied to this kinetic model and $\mathrm{k}_{\mathrm{d}}$ values for each $\mathrm{pH}$, a plot of $\log \mathrm{k}_{\mathrm{d}}$ versus $\mathrm{pH}$ was prepared. The order of the reaction obtained from the plot with respect to $\left[\mathrm{H}^{+}\right]$was proportional to a 0.016 power with a correlation coefficient of 0.99 .

\subsection{Effect of Solid-to-Liquid-Ratio}

Figure 12 gives the zinc recovery as a function of Solidto-liquid-ratio at $333 \mathrm{~K}$ in solutions with $\mathrm{pH}$ of 3 and agitation rate of $700 \mathrm{rpm}$ in different constant times of leaching. According to experimental results presented in Figure 12, it was found that zinc recovery increased until the solid-to-liquid-ratio of $1 / 8$, where about $98 \%$ of zinc recovery was reached. As seen in Figure 12, zinc extraction increases with leaching time at constant solid-toliquid-ratio of $1 / 4$ and $1 / 6$. The maximum zinc recovery at solid-to-liquid-ratio of $1 / 6$ after $5400 \mathrm{sec}$ was about $96 \%$. Therefore, this quantity could be considered an optimum value for the dissolution of zinc with respect to other ratios. A decrease in the solid-to-liquid-ratio increases the rate of leaching due to reduction in amount of ZPR in the solution. Depletion in the amount of ZPR in solution causes an easy diffusion of liquor to the surface of the ZPR particles.

From the effect of solid-to-liquid-ratio on zinc dissolution given in Figure 12, the apparent rate constant was determined. According to $\log \mathrm{k}_{\mathrm{d}} \log (\mathrm{S} / \mathrm{L})$ curves, the order of reaction with respect to solid-to-liquid-ratio was found to be inversely proportional to a 1.34 power with a

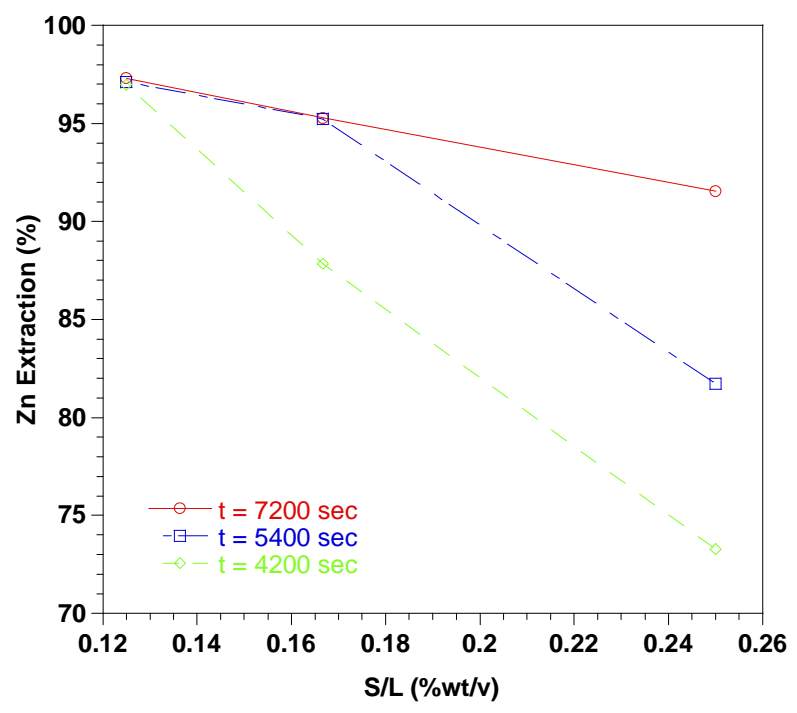

Figure 12. Effect of Solid-to-liquid-ratios on the zinc recovery from the $\mathrm{ZPR}$ in various times, $(\mathrm{pH}$ : 3 ; temperature: $333 \mathrm{~K}$; agitation rate: $700 \mathrm{rpm}$ ).

correlation coefficient of 0.99 .

\subsection{Experimental Equation for Estimating Reaction Rate Constant}

The detailed analysis of leaching kinetics show that activation energy and the order of reaction values with regard to acid concentration and solid-to-liquid-ratio substantiate the shrinking core model (SCM) results for a diffusion controlled process. Hence, the leaching of ZPR can be clearly presented by Equation (20).

$$
\begin{aligned}
& 1-3(1-\alpha)^{\frac{2}{3}}+2(1-\alpha) \\
& =0.001187 \times\left[\mathrm{H}^{+}\right]^{0.016} \times\left[\left(\frac{S}{L}\right)\right]^{-1.34} \times \exp \left(-\frac{1}{R T}\right) \times t
\end{aligned}
$$

As shown in Figure 13, Based on the experimental result, the left-hand side of Equation (20) is plotted against

$$
\left[\mathrm{H}^{+}\right]^{0.016} \times\left[\left(\frac{S}{L}\right)\right]^{-1.34} \times \exp \left(-\frac{1}{R T}\right) \times t
$$

$k_{o}$ value of 0.001187 with a regression coefficient of 0.97 was obtained.

To check the deviation of experimental values of conversion from calculated values from empirical equation, the plot of $G(\alpha)$-experimental against $G(\alpha)$-calculated was drawn. As seen in Figure 14, the agreement between experimental and calculated values was very substantial.

\section{Conclusion}

In the current work, dissolution kinetics of zinc from ZPR in dilute sulfuric acid solution was investigated. It 
was found that the reaction rate increases slightly along with an increase in $\mathrm{pH}$, reaction temperature and also solid-to-liquid-ratio in the range studied. The shrinking core model (SCM) was applied in order to fit the experimental data. Concluded from the experimental work, a diffusion process in the porous product layer controls the leaching reactions. The activation energy of the dissolution process was found to be about $1 \mathrm{~kJ} / \mathrm{mol}$ in the temperature range of $298-353 \mathrm{~K}$. The low values of activetion energy confirm that zinc extraction from ZPR in dilute acid sulfuric solution is not sensitive to temperature. The evaluated activation energy using model-free method was found to be $2.9 \mathrm{~kJ} / \mathrm{mol}$. This value is close to that determined previously, using shrinking core model (SCM) and confirms that the transportation of ions has

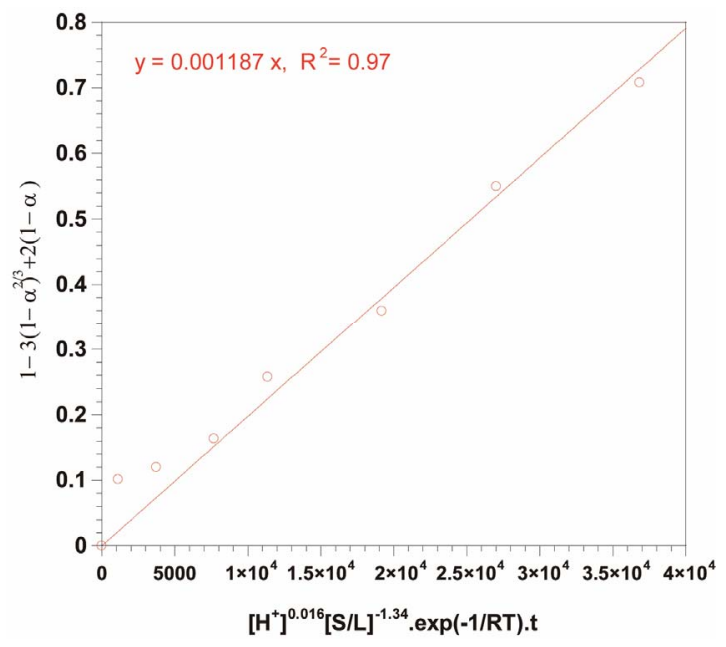

Figure 13. Plot of $1-3(1-a)^{2 / 3}+2(1-a)$ vs

$\left[\mathbf{H}^{+}\right]^{0.016} \times\left[\left(\frac{S}{L}\right)\right]^{-1.34} \times \exp \left(-\frac{1}{R T}\right) \times \mathbf{t},(\mathbf{p H}: 3$; temperature:

$333 \mathrm{~K}$; Solid-to-liquid-ratio: 1/6; agitation rate: $700 \mathrm{rpm}$ ).

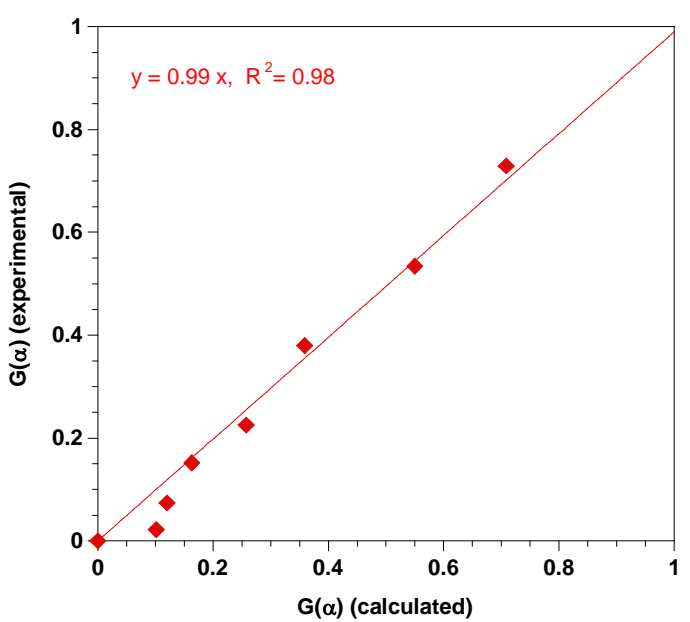

Figure 14. Comparison of experimental and calculated $G(\alpha)$ of zinc in sulfuric acid. been controlled by the rate in this leaching process. The dissolution rate which could be expressed by Equation (20) can be estimated by the reacted fraction. Furthermore, the agreement between the $G(\alpha)$-experimental and $G(\alpha)$-calculated is linear with a regression coefficient of 0.98 . The order of the reaction with respect to $\left[\mathrm{H}^{+}\right]$and solid-to-liquid-ratio was found to be 0.016 and -1.34 , respectively.

\section{Acknowledgements}

The authors would like to acknowledge the Iranian Zinc Mines Development Company, Zanjan, Iran, for financial support and the permission to publish this paper.

\section{REFERENCES}

[1] M. K. Jha, V. Kumar and R. J. Singh, "Review of Hydro-Metallurgical Recovery of Zinc from Industrial Wastes," Resources, Conservation and Recycling, Vol. 33, 2001, pp. 1-22. doi:10.1016/S0921-3449(00)00095-1

[2] M. N. Babu, K. K. Sahu and B. D. Pandey, "Zinc Recovery from Sphalerite Concentrate by Direct Oxidative Leaching with Ammonium, Sodium and Potassium Persulphates," Hydrometallurgy, Vol. 64, No. 2, 2002, pp. 119-129. doi:10.1016/S0304-386X(02)00030-0

[3] A. D. Souza, P. S. Pina, V. A. Leão, C. A. Silva and P. F. Siqueria, "The Leaching Kinetics of a Zinc Sulphide Concen-trate in Acid Ferric Sulphate," Hydrometallurgy, Vol. 89, No. 1-2, 2007, pp. 72-81.

[4] S. Aydogan, "Dissolution Kinetics of Sphalerite with Hydrogen Peroxide in Sulphuric Acid Medium," Chemical Engineering Journal, Vol. 123, 2006, pp. 65-70. doi:10.1016/j.cej.2006.07.001

[5] S. Aydogan, A. Aras and M. Canbazoglu, "Dissolution Ki-Netics of Sphalerite in Acidic Ferric Chloride Leaching," Chemical Engineering Journal, Vol. 114, No. 1-3, 2005, pp. 67-72.

[6] M. Al-Harahsheh and S. Kingman, "The Influence of Microwaves on the Leaching of Sphalerite in Ferric Chloride," Chemical Engineering and Processing, Vol. 46, No. 10, 2007, pp. 883-888. doi:10.1016/j.cep.2007.06.009

[7] P. Peng, H. Xie and L. Lu, "Leaching of a Sphalerite Concentrate with $\mathrm{H}_{2} \mathrm{SO}_{4}-\mathrm{HNO}_{3}$ Solutions in the Presence of $\mathrm{C}_{2} \mathrm{C}_{14}$," Hydrometallurgy, Vol. 80, No. 4, 2005, pp. 265-271. doi:10.1016/j.hydromet.2005.08.004

[8] J. S. Niederkorn, "Kinetic Study on Catalytic Leaching of Sphalerite," Journal of Marine Engineering and Technology, Vol. 37, No. 7, 1985, pp. 53-56.

[9] S. Espiari, F. Rashchi and S. K. Sadrnezhaad, "Hydrometallurgical Treatment of Tailings with High Zinc Content," Hydrometallurgy, Vol. 82, No. 1-2, 2006, pp. 54-62.

[10] B. K. Thomas and D. J. Fray, "Leaching of Oxidic Zinc Materials with Chlorine and Chlorine Hydrate," Metallurgical Transactions, Vol. 12, No. 2, 1981, pp. 281-285. doi:10.1007/BF02654461 
[11] J. Frenay, "Leaching of Oxidised Zinc Ores in Various Media," Hydrometallurgy, Vol. 15, 1985, pp. 243-253. doi:10.1016/0304-386X(85)90057-X

[12] E. A. Abdel-Aal, "Kinetics of Sulfuric Acid Leaching of Low-Grade Zinc Silicate Ore," Hydrometallurgy, Vol. 55, 2000, pp. 247-254. doi:10.1016/S0304-386X(00)00059-1

[13] A. D. Souza, P. S. Pina, E. V. O. Lima, C. A. Da Silva and V. A. Leão, "Kinetics of Sulphuric Acid Leaching of A Zinc Silicate Calcine," Hydrometallurgy, Vol. 89, No. 3, 2007, pp. 337-345. doi:10.1016/j.hydromet.2007.08.005

[14] M. G. Bodas, "Hydrometallurgical Treatment of Zinc Silicate Ore from Thailand," Hydrometallurgy, Vol. 40, No. 1-2, 1996, pp. 37-49.

[15] Y. Zhao and R. Stanforth, "Production of Zn Powder by Alkaline Treatment of Smithsonite $\mathrm{Zn}-\mathrm{Pb}$ Ores," Hydrometallurgy, Vol. 56, No. 2, 2000, pp. 237-249. doi:10.1016/S0304-386X(00)00079-7

[16] M. Kul and Y. Topkaya, "Recovery of Germanium and Other Valuable Metals from Zinc Plant Residues," $\mathrm{Hy}$ drometallurgy, Vol. 92, No. 3-4, 2008, pp. 87-94.

[17] Y. Wang and Z. Chunshan, "Hydrometallurgical Process for Recovery of Cobalt from Zinc Plant Residue," $H y$ drometallurgy, Vol. 63, No. 3, 2002, pp. 225-234. doi:10.1016/S0304-386X(01)00213-4

[18] A. Ruşen, A. S. Sunkar and Y. A. Topkaya, "Zinc and Lead Extraction from Çinkur Leach Residues by Using Hydrometallurgical Method," Hydrometallurgy, Vol. 93, No. 1-2, 2008, pp. 45-50.

[19] F. Farahmand, D. Moradkhani, M. S. Safarzadeh and F. Rashchi, "Brine Leaching of Lead-Bearing Zinc Plant Residues: Process Optimization Using Orthogonal Array Design Methodology," Hydrometallurgy, Vol. 95, No. 3-4, 2009, pp. 316-324.

[20] S. Kikuchi, T. Goto and A. Nakayama, "Recovery of Zinc from Leaching Residue in Zinc Hydrometallurgy by TOPO," Journal of the Mining and Metallurgical Institute of Japan, Vol. 101, No. 1168, 1985, pp. 381-385.

[21] K. L. Bhat and K. A. Natrajan, "Recovery of Zinc from Leach Residues-Problems and Developments," Transactions of the Indian Institute of Metals, Vol. 40, No. 4, 1987, p. 361.

[22] A. V. Ropenack, W. Bohmer, G. Smykalla and V. Wiegand, "Method of Processing Residues from the Hydrometallurgical Production of Zinc," US Patent No. 4789446, 1987.

[23] F. J. J. B. Bodson, "Recovery of Zinc Values from Zinc Plant Residue," US Patent No. 3652264, 1972.

[24] Z. Youcai and R. Stanforth, "Extraction of Zinc from Zinc Ferrites by Fusion with Caustic Soda," Mineral Engineering, Vol. 13, No. 13, 2000, pp. 1417-1421.

[25] L. J. L. Blanco, V. F. M. Zapata and D. D. Garcia, "Statistical Analysis of Laboratory Results of $\mathrm{Zn}$ Wastes Leaching," Hydrometallurgy, Vol. 54, No. 1, 1999, pp.

\section{1-48. doi:10.1016/S0304-386X(99)00057-2}

[26] M. D. Turan, H. S. Altundoğan and F. Tumen, "Recovery of Zinc and Lead from Zinc Plant Residue," Hydrometallurgy, Vol. 75, No. 1-4, 2004, pp. 169-176. doi:10.1016/j.hydromet.2004.07.008

[27] T. Pecina, T. Franco, P. Castillo and E. Orrantia, "Leaching of a Zinc Concentrate in $\mathrm{H}_{2} \mathrm{SO}_{4}$ Solutions Containing $\mathrm{H}_{2} \mathrm{O}_{2}$ and Complexing Agents," Minerals Engineering, Vol. 21, No. 1, 2008, pp. 23-30. doi:10.1016/j.mineng.2007.07.006

[28] H. Y. Sohn and M. E. Wadsworth, "Rate Processes of Extractive Metallurgy,” Plenum Press, New York, 1979. doi:10.1007/978-1-4684-9117-3

[29] M. K. Ghosh, R. P. Das and A. K. Biswas, "Oxidative Ammonia Leaching of Sphalerite-Part I: Noncatalytic Kinetics," International Journal of Mineral Processing, Vol. 66, No. 1, 2002, pp. 241-254. doi:10.1016/S0301-7516(02)00068-6

[30] M. K. Ghosh, R. P. Das and A. K. Biswas, "Oxidative Ammonia Leaching of Sphalerite: Part II: $\mathrm{Cu}(\mathrm{II})$-Catalyzed Kinetics," International Journal of Mineral Processing, Vol. 70, No. 1-4, 2003, pp. 221-234.

[31] O. Levenspiel, "Chemical Reaction Engineering," 2nd Edition, Wiley, New York, 1999.

[32] S. Vyazovkin and W. A. Charles, "Model-Free and Model-Fitting Approaches to Kinetic Analysis of Isothermal and Nonisothermal Data," Thermochimica Acta, Vol. 340-341, 1999, pp. 53-68. doi:10.1016/S0040-6031(99)00253-1

[33] S. Vyazovkin, "Computational Aspects of Kinetic Analysis: Part C. The ICTAC Kinetics Project-the Light at the End of the Tunnel?" Thermochimica Acta, Vol. 355, No. 1, 2000, pp. 155-163. doi:10.1016/S0040-6031(00)00445-7

[34] M. S. Safarzadeh, D. Moradkhani and M. O. Ilkhchi, "Kinetics of Sulfuric Acid Leaching of Cadmium from Cd-Ni Zinc Plant Residues," Journal of Hazardous Materials, Vol. 163, No. 2-3, 2009, pp. 880-890.

[35] W. L. Choo, M. I. Jeffrey and S. G. Robertson, "Analysis of Leaching and Cementation Reaction Kinetics: Correcting for Volume Changes in Laboratory Studies," $\mathrm{Hy}$ drometallurgy, Vol. 82, No. 1-2, 2006, pp. 110-116.

[36] R. Vaghar, "Hydrometallurgy," Iranian Copper Industry Co., Iran, 1998.

[37] D. Dreisinger and N. Abed, "A Fundamental Study of the Reductive Leaching of Chalcopyrite Using Metallic Iron Part I: Kinetic Analysis," Hydrometallurgy, Vol. 66, No. 1, 2002, pp. 37-57. doi:10.1016/S0304-386X(02)00079-8

[38] M. K. Sarker, A. K. M. B. Rashid and A. S. W. Kurny, "Kinetics of Leaching of Oxidized and Reduced Ilmenite in Dilute Hydrochloric Acid Solutions," International Journal of Mineral Processing, Vol. 80, No. 2-4, 2006, pp. 223-228. doi:10.1016/j.minpro.2006.04.005 